\title{
Psychic Decline, Diogenes Syndrome and Parental Capacity
}

\author{
Tiffon $\mathrm{BN}^{1 *}$ and Gonzalez $\mathrm{J}^{2}$ \\ ${ }^{1}$ Professor of Legal Psychology, Abat Oliba CEU University, Spain \\ ${ }^{2}$ Coroner, Director of La Rioja Institute of Legal Medicine and Forensic Sciences, Spain
}

*Corresponding author: Bernat N Tiffon, Abat Oliba CEU University, Calle de Bellesguard, no30. 08022, Barcelona, Spain, Tel: +34650402838; Email: btiffonn@uao.es

\section{Case Report \\ Volume 5 Issue 2}

Received Date: November 11, 2021

Published Date: December 07, 2021

DOI: $10.23880 / \mathrm{mhrij}-16000156$

\section{Abstract}

A process of adoption of a minor is analysed in which the adoptive parents suffer from mental disorders and live in an unhealthy physical context of Diogenes Syndrome. Said psychopathological condition of the adoptive parent candidates is not only established by the accreditation of the documentation and clinical history of both, but also with the visual observation of the physical conditions of the home in which the minor was intended to be welcomed. From both of the aforementioned elements (clinical documentation and visual inspection of the home of the adoptive parents candidates), the subsequent expert non-intervention was determined to assess the parental capacity of the adoption applicants.

Keywords: Psychic Decline; Diogenes Syndrome; Parental Capacity; Adoption

\section{Introduction}

Diogenes Syndrome (named after the Greek philosopher and cynic) is a neurobehavioral syndrome characterized by a severe abandonment of self-care with a tendency to domestic misery, which includes a pathological accumulation of waste, garbage or useless objects, compulsive hoarding, lack of shame regarding unsanitary or unhygienic living conditions, and denial or lack of awareness of the disease (anosognosia), the latter being what prevents most of these people from seeking medical or psychological help [1-3]. Adult subjects with this syndrome usually present a complex and unique behaviour that is the manifest expression of comorbid pathological personality traits, characterized by a combination of evasive, paranoid and anankastic (or obsessive) traits. Thus, subjects are susceptible to mistrust, suspicion and hypervigilance (typical of people with paranoid personality traits, subjects characterized by being obsessive and/or meticulous (typical of subjects with anankastic personality traits), or subjects socially characterized by being avoidant (typical of subjects with avoidant personality traits), are those most likely to develop this type of syndrome. However, although the carelessness and lack of hygiene of these patients may be evident, one must always be cautious regarding the clinical phenomenology and always carry out an accurate differential diagnosis to avoid iatrogenic praxis. Two types of Diogenes Syndrome have been described according to their behaviour regarding the accumulation of objects: the Active type, or collector of objects that they store at home; and the Passive type that passively allows them to be overwhelmed by the build-up of their own garbage [4].

\section{The Case}

The case deals with a cohabitating couple, both of whose basic psychic pathology was of a developmental disorder (psychic decline that ranged between ModerateMild-Borderline degrees). Although said psychopathology was already accredited by public clinical-health entities and they presented a declaration of disability for which they both received a pension, they expressed to their lawyer their desire to be parents by the adoption of a minor. The legal director of the matter explained the reason for his clients' consultation with the Mental Health professional, who, once he had viewed the content of the clinical documentation that was provided, reported unfavourably, indicating the 


\section{Mental Health \& Human Resilience International Journal}

unfeasibility of the adoption proposal. The clinical history was highly enlightening regarding the diagnosis of both members of the couple, which made their possible parental capacity unfeasible and, therefore, the inviability of adopting a minor. Despite the aforementioned, the couple insisted on their claims, in such a way that, given the obstinacy and obsessiveness of their desire to be parents, the candidates were recognized. Given their precarious economic conditions and basic mental condition, the expert went to their house in order to carry out an evaluation "in situ".

On arriving at the residence of the subjects in order to be able to assess the house and meet them in person, a member of the couple opened the door, revealing, with their initial greeting, the underlying pathology for which they obtained their degree of disability due to mental impairment. In that moment, the other member of the couple appeared, inviting the evaluator to enter the house. Once through the door, there was a perceptible damp stench, a notable accumulation of dust on the furniture, with a state of neglect in the house, poor hygiene and an accumulation of objects and bags that revealed, and fully confirmed, the diagnoses established in the first instance by medical specialists in mental health from the public health institutions [5]. Having stated the above, and based on what was evidenced by the evaluator who was going to psychopathologically examine the paternal candidates, it was not considered necessary to carry out said psychic evaluation, aborting any subsequent expert intervention.

\section{Discussion and Conclusion}

The context described above exposes some of the multiple circumstances by which an expert in Mental Health (be it a psychologist or a psychiatrist) can be immersed in a juridical-legal procedure (either at the beginning of a case or in later developments in a procedure that has already begun). In the present case, the application of the candidates could not continue to be considered, not only due to the basic psychopathological conditions, already accredited with the existing clinical documentation, but also from the physical conditions of the potential home for an adopted child, which were utterly unhealthy, unsuitable and not ideal for the adequate upbringing of a minor. The initial circumstances of the case already led to a complex situation, confirmed with the inspection of the physical living conditions in which a minor was supposed to live, who would have been immersed in an environment of Diogenes Syndrome with the consequent harmful and negative influence on their psychophysical development.

\section{References}

1. Fontenelle LF (2008) Diogenes Syndrome in a patient with obsessive-compulsive disorder without hoarding. Gen Hosp Psychiatry 30(3): 288-290.

2. Sacchi L, Rotondo E, Pozzoli S, Fiorentini A, Schinco G, et al. (2021) Diogenes syndrome in dementia: a case report. BJPsych Open 7(2): 1-5.

3. Tiffon BN (2021) Psychic decline, Diogenes syndrome and parental capacity. Probatic Law No. 5, Editorial Wolters Kluwer, Madrid, Spain.

4. Hanon C, Pinquier C, Gaddour N, Said S, Mathis D, et al. (2004) Diogenes Syndrome: A transnosographic approach. Encephale 30(4): 315-322.

5. Tiffon BN, Gonzalez J (2021) Sexual sadism towards a minor and Diogenes Syndrome with the hiding of a cadaver. Asesan Journal of Psychiatry 22(9): 1-8. 